\title{
Initial orthostatic hypotension among patients with unexplained syncope: An overlooked diagnosis?
}

Citation for published version (APA):

van Twist, D. J. L., Dinh, T., Bouwmans, E. M. E., \& Kroon, A. A. (2018). Initial orthostatic hypotension among patients with unexplained syncope: An overlooked diagnosis? International Journal of Cardiology, 271, 269-273. https://doi.org/10.1016/j.ijcard.2018.05.043

Document status and date:

Published: 15/11/2018

DOI:

10.1016/j.ijcard.2018.05.043

Document Version:

Publisher's PDF, also known as Version of record

Document license:

Taverne

Please check the document version of this publication:

- A submitted manuscript is the version of the article upon submission and before peer-review. There can be important differences between the submitted version and the official published version of record.

People interested in the research are advised to contact the author for the final version of the publication, or visit the DOI to the publisher's website.

- The final author version and the galley proof are versions of the publication after peer review.

- The final published version features the final layout of the paper including the volume, issue and page numbers.

Link to publication

\footnotetext{
General rights rights.

- You may freely distribute the URL identifying the publication in the public portal. please follow below link for the End User Agreement:

www.umlib.nl/taverne-license

Take down policy

If you believe that this document breaches copyright please contact us at:

repository@maastrichtuniversity.nl

providing details and we will investigate your claim.
}

Copyright and moral rights for the publications made accessible in the public portal are retained by the authors and/or other copyright owners and it is a condition of accessing publications that users recognise and abide by the legal requirements associated with these

- Users may download and print one copy of any publication from the public portal for the purpose of private study or research.

- You may not further distribute the material or use it for any profit-making activity or commercial gain

If the publication is distributed under the terms of Article $25 \mathrm{fa}$ of the Dutch Copyright Act, indicated by the "Taverne" license above, 


\title{
Initial orthostatic hypotension among patients with unexplained syncope: An overlooked diagnosis?
}

\author{
Daan J.L. van Twist ${ }^{\mathrm{a}, \mathrm{b}, *}$, Trang Dinh ${ }^{\mathrm{c}}$, Esther M.E. Bouwmans ${ }^{\mathrm{b}}$, Abraham A. Kroon ${ }^{\mathrm{b}}$ \\ a Department of Internal Medicine, Zuyderland Medical Centre, Geleen/Heerlen, The Netherlands \\ b Department of Internal Medicine, subdivision of Vascular Medicine, Maastricht University Medical Centre, Maastricht, The Netherlands \\ c Department of Cardiology, Maastricht University Medical Centre, Maastricht, The Netherlands
}

\section{A R T I C L E I N F O}

\section{Article history:}

Received 20 December 2017

Received in revised form 3 May 2018

Accepted 14 May 2018

\section{Keywords:}

Initial orthostatic hypotension

Syncope

Orthostatic hypotension

Blood pressure

\begin{abstract}
A B S T R A C T
Background: Initial orthostatic hypotension ( $\mathrm{IOH})$ is a clinical syndrome of transient orthostatic hypotension that is defined as a drop in blood pressure of $>40 \mathrm{~mm} \mathrm{Hg}$ systolic and/or $>20 \mathrm{~mm} \mathrm{Hg}$ diastolic within $15 \mathrm{~s}$ after standing, accompanied by symptoms of cerebral hypoperfusion, but without sustained orthostatic hypotension (blood pressure decrease $>20 / 10 \mathrm{~mm} \mathrm{Hg}$ after 1-3 min of standing). As the etiology of syncope remains unknown in a large proportion of patients, we hypothesized that $\mathrm{IOH}$ is highly prevalent among patients with unexplained syncope.

Methods: We studied 250 consecutive outpatients with unexplained syncope that were evaluated in the syncopeunit of our tertiary referral hospital. We measured hemodynamic changes in response to active standing using a beat-to-beat blood pressure measurement device, first after lying supine for $>5 \mathrm{~min}$ and then after squatting for $30 \mathrm{~s}$.

Results: $11.2 \%$ of the patients were diagnosed with syncope due to $\mathrm{IOH}$, with a mean fall in blood pressure of $47.4 \pm$ $12.5 / 29.0 \pm 10.7 \mathrm{~mm} \mathrm{Hg}$ within $15 \mathrm{~s}$ after standing up. Therefore, IOH was the second commonest cause of syncope in our cohort. $46.2 \%$ of the patients diagnosed with syncope due to IOH used antihypertensive drugs, mostly betablockers (41.6\%) and/or tamsulosin (24.9\%). The squatting-to-standing-test in addition to the lying-tostanding-test resulted in only 3 additional patients diagnosed with syncope due to $\mathrm{IOH}$.

Conclusions: $\mathrm{IOH}$ is highly prevalent among patients with previously unexplained syncope. Therefore, beat-to-beat blood pressure measurement should be considered in patients with unexplained syncope.
\end{abstract}

(c) 2018 Elsevier B.V. All rights reserved.

\section{Introduction}

Initial orthostatic hypotension ( $\mathrm{IOH})$ is a clinical syndrome of transient orthostatic hypotension that results in dizziness and/or syncope shortly after standing up actively, but not on passive tilting [1]. It is defined as a decrease in blood pressure of at least $40 \mathrm{~mm} \mathrm{Hg}$ systolic and/ or $20 \mathrm{~mm} \mathrm{Hg}$ diastolic within $15 \mathrm{~s}$ after standing up, accompanied by symptoms of cerebral hypoperfusion, but in the absence of sustained orthostatic hypotension (blood pressure decrease $>20 / 10 \mathrm{~mm} \mathrm{Hg}$ after 1 3 min of standing) [2]. Diagnosing IOH can be difficult due to the rapid changes in blood pressure. Hence, it cannot be detected with an intermittent (upper arm) blood pressure measurement, but only with continuous measurement of blood pressure during active standing (example in Fig. 1). As a result, its exact prevalence is still unclear. Since the etiology of syncope remains unknown in up to $33 \%$ of the patients [3-7], we hypothesized that IOH might be an important cause of

\footnotetext{
* Corresponding author at: Department of Internal Medicine, Zuyderland Medica Centre, PO-box 5500, 6130 MB Sittard, The Netherlands.

E-mail address: d.vantwist@zuyderland.nl (D.J.L. van Twist).
}

syncope among patients with unexplained syncope. Therefore, we evaluated a cohort of 250 patients with previously unexplained syncope for the presence of $\mathrm{IOH}$ by measuring hemodynamic changes (using a beatto-beat blood pressure measurement device) in response to standing up actively from the lying position. As the fall in blood pressure is generally larger in case of standing up from the squatting position than from the lying position [1], we hypothesized that the squatting-to-standing-test would be more sensitive to detect $\mathrm{IOH}$. Therefore, we also evaluated hemodynamic changes in response to standing up from the squatting position.

\section{Methods \\ 2.1. Patients and protocol}

We reviewed data from 250 consecutive outpatients who were analysed because of unexplained syncope in the multidisciplinary syncope unit of our tertiary referral hospital between September 2015 and May 2017. All patients were previously analysed in a secondary hospital or in the emergency department, but were referred to our syncope unit as those analyses did not lead to a definitive diagnosis, i.e. the cause of syncope remained unexplained. Analysis in such multidisciplinary syncope unit is highly recommended as it reduces hospitalization, costs, and presumably the number of misdiagnosis [8]. In our 


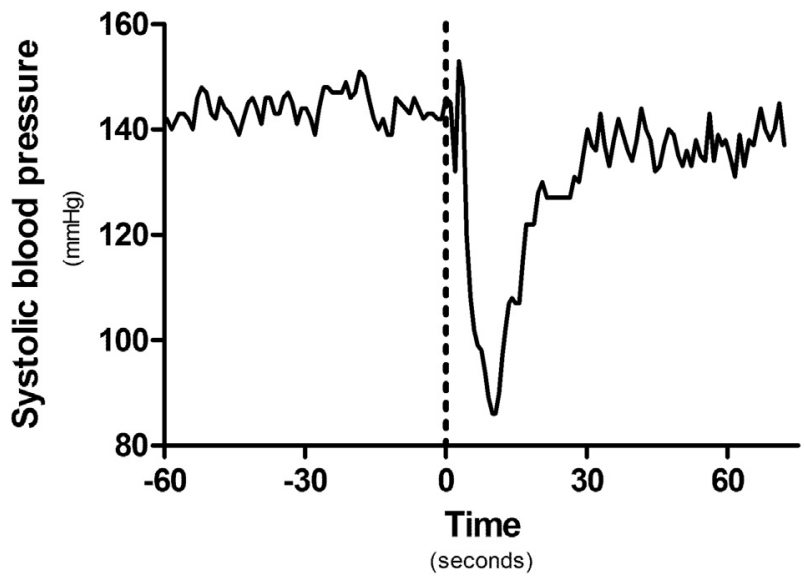

Fig. 1. Example of initial orthostatic hypotension. Beat-to-beat blood pressure measurement of a 60-year-old man standing up from the lying position (lying-tostanding-test), revealing initial orthostatic hypotension. Dotted line at $t=0$ indicates time of standing up. Note the transient fall in blood pressure shortly after standing up, which was accompanied by a sensation of lightheadedness.

syncope unit, all patients were evaluated according to the same, standard clinical protocol. First, history was taken by two syncope experts ( simultaneously): a cardiologist and either a neurologist or an internist/vascular medicine specialist. Subsequently, all patients underwent a standard diagnostic protocol, including electrocardiography, echocardiography, a beat-to-beat blood pressure measurement (see below), and laboratory testing (all on the same day). If considered clinically indicated additional tests were performed, such as long-term heart rhythm monitoring, cardiac exercise test, autonomic function tests (including Valsalva maneuver, deep breathing test, and carotid sinus massage), head-up tilt-table testing, electroencephalography, or additional imaging of the heart, brain, or vascular system. Thereafter, the diagnosis was established by consensus among the two syncope experts. In case of disagreement or doubt about the diagnosis, the case was reviewed by a multidisciplinary expert panel, consisting of (at least) one cardiologist, one neurologist, and one internist/vascular medicine specialist. Their consensus was decisive for the final diagnosis. The study was approved by the Medical Ethics Committee of the Maastricht University Medical Centre and complies with the Declaration of Helsinki. According to the Dutch law no written informed consent was needed because of the retrospective design of the study.

\subsection{Measurements}

We measured hemodynamic changes in response to active standing using a Nexfin device (BMEYE, Amsterdam, The Netherlands), a non-invasive, beat-to-beat blood pressure measurement device that measures arterial blood pressure continuously using the volume clamp method, reconstructs finger blood pressure to brachial blood pressure, and adjusts for vertical difference between the finger and heart based on height sensor. Reproducibility of these measurements (both under standardized and non-standardized conditions) has been evaluated previously [9-11]. The measurements were performed in a non-fasting state, between 1.00 and 4.30 p.m. in a quiet room maintained in a temperature of $21-23^{\circ} \mathrm{C}$. The finger cuff was applied around the middle finger of the right hand (size according to the manufacturer's instructions). The height sensor was placed on the chest at heart level and on the index finger of the right hand. Thereafter, baseline blood pressure recording was initiated while lying supine. Baseline blood pressure was verified with a digital upper arm blood pressure monitor (Omron M3, Omron Healthcare, Lake Forest, IL, USA) in order to detect measurement problems of the beat-to-beat blood pressure measurement device. In most cases, the finger cuff had to be replaced, but in case of other (unsolvable) measurement problems the patients were excluded from the present analysis. After at least $5 \mathrm{~min}$ of lying supine, the patients were instructed to stand up actively (in a timely manner) and stand still for 3 min (lying-to-standing-test). Thereafter, the patients were instructed to squat for 30-60 s (until blood pressure maintained stable) and then stand up (within $3 \mathrm{~s}$ ) and stand still for $1 \mathrm{~min}$ (squatting-to-standing-test). During the whole test, beat-to-beat blood pressure was recorded. Shortly after standing up, the patient was asked whether symptoms of cerebral hypoperfusion had occurred (e.g. lightheadedness or dizziness).

\subsection{Analyses}

After the measurements we evaluated changes in blood pressure and heart rate upon active standing. As the beat-to-beat variation in blood pressure can be relatively large, we took the average blood pressure during the last $15 \mathrm{~s}$ before standing up as the baseline value. For the nadir of blood pressure within $15 \mathrm{~s}$ after standing up we took the average of 3 blood pressure values around the nadir. For the blood pressure after 1 and 3 min of standing the average during $15 \mathrm{~s}$ was taken.
Patients were diagnosed with syncope due to $\mathrm{IOH}$ if they met all of the following criteria:

1) Blood pressure criteria: Fall in blood pressure within $15 \mathrm{~s}$ after standing up of $>40 \mathrm{~mm} \mathrm{Hg}$ systolic and/or $>20 \mathrm{~mm} \mathrm{Hg}$ diastolic (measured at nadir).

2) Recognizable symptoms of hypoperfusion (e.g. light-headedness or dizziness).

3) No sustained orthostatic hypotension after 1 or $3 \mathrm{~min}$ (fall in blood pressure of $>20 \mathrm{~mm} \mathrm{Hg}$ systolic and/or $10 \mathrm{~mm} \mathrm{Hg}$ diastolic).

4) History of syncope shortly after standing up (within $15 \mathrm{~s}$ ), with $\mathrm{IOH}$ as the most likely clinical diagnosis (based on history taking by 2 syncope experts).

5) The absence of any clues for alternative diagnoses on additional diagnostic tests.

In case of any doubt on the diagnosis the case was reviewed by a multidisciplinary expert panel of at least 1 cardiologist, 1 neurologist, and 1 vascular-medicine specialist. The use of blood pressure lowering drugs was defined as the use of drugs that are known to lower blood pressure (beta-blockers, alpha-blockers, angiotensin-converting-enzyme inhibitors, angiotensin receptor blockers, calcium channel blockers, nitrates, or diuretics), irrespective whether it was prescribed for hypertension or for another indication (for example: alpha-blockers for lower urinary tract symptoms). We used SPSS (SPSS Inc., version 23.0, Chicago, Illinois, USA) for the statistical analyses. $t$-Tests (paired and unpaired) were used for continuous data (all normally distributed; expressed as mean \pm S.D.) and chi square test was used to assess categorical data. Correlation was tested using Pearson's R. A p-value of $<0.05$ was considered statistically significant.

\section{Results}

\subsection{Patient characteristics}

Out of 250 patients that were evaluated, 17 patients had to be excluded from the analyses of the beat-to-beat blood pressure data: 10 because of technical failure during the measurement, 2 because of data storage problems, 3 because of difficulties in evaluating the data due to heart rhythm abnormalities, and 2 because of the presence of a neurostimulator that interfered with the measurements. Therefore, beat-to-beat blood pressure data from 233 patients were available for analysis. Patient characteristics are summarized in Table 1. On average, patients were $61.7 \pm 17.6$ years old, with an average blood pressure of $132 \pm 22 / 76 \pm 11 \mathrm{~mm} \mathrm{Hg}$ (measured lying supine with a beat-to-beat blood pressure measurement device). $53.6 \%$ was female and $23.2 \%$ had a previous cardiovascular event.

\subsection{Lying-to-standing-test}

Out of 233 patients who underwent the lying-to-standing-test, 116 patients had a normal blood pressure response with an average fall in blood pressure within $15 \mathrm{~s}$ after standing of $11.7 \pm 20.7 \mathrm{~mm} \mathrm{Hg}$ systolic and $5.7 \pm 12.7 \mathrm{~mm} \mathrm{Hg}$ diastolic (Supplemental Fig. 1). 117 patients met the blood pressure criteria for $\mathrm{IOH}$ with a mean drop in blood pressure of $47.0 \pm 14.4 \mathrm{~mm} \mathrm{Hg}$ systolic and $29.3 \pm 12.0 \mathrm{~mm} \mathrm{Hg}$ diastolic within $15 \mathrm{~s}$ after standing up (Supplemental Fig. 1). However, as shown in Fig. 2a, 64 of these patients reported no recognizable symptoms of cerebral hypoperfusion during the test, 7 patients had sustained orthostatic hypotension, and in 23 patients an alternative diagnosis was considered more likely (alternative diagnoses are shown in Supplemental Table 1). Hence, 23 out of 233 patients were diagnosed with syncope due to $\mathrm{IOH}$ based on the lying-to-standing-test.

\subsection{Squatting-to-standing-test}

The squatting-to-standing-test was only performed in a subgroup 155 patients. The reason for this was that many patients had joint problems or were too frail to (safely) stand-up after squatting. Of these 155 patients, 127 met the blood pressure criteria for IOH with a mean fall in blood pressure of $49.4 \pm 17.6 / 35.4 \pm 13.1 \mathrm{~mm} \mathrm{Hg}$ within $15 \mathrm{~s}$ after standing up (Supplemental Fig. 2). However, as shown in Fig. 2b, 73 of these patients reported no recognizable symptoms of cerebral hypoperfusion during the test, 9 patients had sustained orthostatic hypotension, and in 35 patients an alternative diagnosis was considered more likely (Supplemental Table 1 ). Hence, only 10 out of 155 patients were diagnosed with syncope due to $\mathrm{IOH}$ after the squatting-to-standing-test. Of 
Table 1

Characteristics of the patients.

\begin{tabular}{ll}
\hline Patient characteristic & $\mathrm{n}=233$ \\
\hline Female $(\mathrm{n}(\%))$ & $125(53.6 \%)$ \\
Age (years) & $61.7 \pm 17.6$ \\
Body mass index $\left(\mathrm{kg} / \mathrm{m}^{2}\right)$ & $26.7 \pm 4.4$ \\
Current smoking $(\mathrm{n}(\%))$ & $34(14.6 \%)$ \\
Previous cardiovascular event (n (\%)) & $54(23.2 \%)$ \\
Previously diagnosed hypertension (n (\%)) & $93(39.9 \%)$ \\
Diabetes mellitus (n (\%)) & $31(13.3 \%)$ \\
Current use of blood pressure lowering drugs (n (\%)) & $116(49.8 \%)$ \\
Current us of antidepressants (n (\%)) & $41(17.6 \%)$ \\
eGFR (mL/min/1.73 m $\left.{ }^{2}\right)$ & $74 \pm 23$ \\
Hemoglobin level (mmol/L) & $8.6 \pm 0.9$ \\
LDL (mmol/L) & $2.9 \pm 1.1$ \\
LVEF $(\%)$ & $58.8 \pm 6.7$ \\
\hline
\end{tabular}

Characteristics of the study patients. Values expressed as mean \pm S.D. eGFR indicates estimated glomerular filtration rate using the CKD-EPI formula; LDL, low-density lipoprotein; LVEF, left ventricular ejection fraction.

these, 7 were already detected with the lying-to-standing-test. Therefore, the squatting-to-standing-test resulted in 3 extra diagnosis of $\mathrm{IOH}$ in addition to the lying-to-standing-test.

\subsection{Patients with $\mathrm{IOH}$}

In total, 26 out of 233 patients (11.2\%) were diagnosed with syncope due to $\mathrm{IOH}$. Therefore, $\mathrm{IOH}$ was the second commonest cause of syncope in our cohort (Table 2). Mean fall in blood pressure among the patients diagnosed with syncope due to $\mathrm{IOH}$ was $47.4 \pm 12.5 / 29.0 \pm$ $10.7 \mathrm{~mm} \mathrm{Hg}$, with an increase in heart rate of $14.0 \pm 15.6$ beats per minute (Supplemental Fig. 3). Three of the 26 patients were diagnosed by the diastolic blood pressure fall only (i.e. drop in systolic blood pressure was $<40 \mathrm{~mm} \mathrm{Hg}$, but drop in diastolic blood pressure was $>20 \mathrm{~mm} \mathrm{Hg}$ ). Of the patients diagnosed with syncope due to $\mathrm{IOH}$, $46.2 \%$ of the patients used antihypertensive drugs [mostly betablockers (41.6\%) and/or tamsulosin (24.9\%)] and 19.2\% used antidepressant drugs. The use of these drugs by patients diagnosed with syncope due to IOH did not significantly differ from that by patients diagnosed with other causes of syncope. No differences were found between patients diagnosed with syncope due to $\mathrm{IOH}$ and the other patients with regard to age, gender, height, BMI, medical history, baseline blood pressure, or other patient characteristics (listed in Supplemental Table 2).

Eventually, the cause of syncope remained idiopathic in 26 patients (Table 2). Of those, 5 patients met the blood pressure criteria for $\mathrm{IOH}$ on the lying-to-standing-test and 8 on the squatting-to-standing-test. However, as history did not reveal that syncope was preceded by an active standing maneuver, the expert panel considered it unlikely that $\mathrm{IOH}$ was the cause of syncope in these patients. Hence, the cause of syncope in these patients was classified as idiopathic.

\section{Discussion}

In the present study we found that $\mathrm{IOH}$ is the second commonest cause of syncope (11.2\%) among outpatients who were referred to our tertiary hospital because of previously unexplained syncope. Previous data on the prevalence of $\mathrm{IOH}$ among patients with syncope are scarce. In a study among 371 young adults ( $<30$ years) with syncope, $7 \%$ was diagnosed with syncope due to $\mathrm{IOH}[12]$. In that study, however, the diagnosis of IOH was based on history taking only. In a similar study among 503 patients with syncope, history taking alone pointed towards $\mathrm{IOH}$ in $3.6 \%$ of the cases $[1,13]$. Interestingly, the prevalence of $\mathrm{IOH}$ in our study was substantially higher. This may be caused by the fact that we studied a selected population of patients with unexplained syncope despite previous analysis in secondary hospitals or the emergency department. Furthermore, we measured hemodynamic changes upon standing in all patients, which inevitably increased awareness on initial orthostatic hypotension among doctors and patients.

Establishing the diagnosis of $\mathrm{IOH}$ is important for appropriate patient management. Volume expansion, sodium supplementation, interruption of interfering medication, instructions to stand up slowly, and counter maneuvers such as buttock clenching can improve quality of life and prevent recurrent syncope $[1,12,14]$. Moreover, it may reduce health care consumption as many patients are referred for additional diagnostic testing or second opinion as long as the cause of syncope remains unclear. The beat-to-beat blood pressure data could be used for patient education. In our experience, this can be very helpful for patients in understanding the cause of their symptoms and to demonstrate the efficacy of counter maneuvers. Unfortunately, beat-to-beat blood pressure measurement devices are not widely available yet, while intermittent (upper arm) blood pressure measurement is not able to detect the rapid changes in blood pressure that occur in $\mathrm{IOH}$. In those settings $\mathrm{IOH}$ should still be considered as a working diagnosis in case of a typical clinical history.

In this study, we found that $50.2 \%$ of the patients met the blood pressure criteria for $\mathrm{IOH}$, while $\mathrm{IOH}$ was considered the cause of syncope in "only" $11.2 \%$ of the patients. This large number of "false-positive" patients is to be expected, as a large population study demonstrated that $\mathrm{IOH}$ occurs in $32.9 \%$ of the population above 50 years old [15]. Interestingly, the presence of $\mathrm{IOH}$ in these relatively healthy subjects is not associated with an increased risk for syncope on the long term [16]. Therefore we would like to emphasize that history taking remains the cornerstone in the evaluation of unexplained syncope. Beat-to-beat blood pressure measurement can be a helpful diagnostic tool, but the diagnosis of $\mathrm{IOH}$ should only be made if history taking and other diagnostic tests point towards $\mathrm{IOH}$ as well. Conversely, natural intra-individual variation in blood pressure could lead to false-negative test-results [17], while IOH was present at the time of syncope for example due to volume depletion or a lower baseline blood pressure in the early morning. Therefore, in case of high clinical suspicion, repeated measurements should be considered to establish the diagnosis of $\mathrm{IOH}$.

The squatting-to-standing-test in addition to the lying-to-standingtest resulted in only 3 additional patients diagnosed with syncope due to IOH. Given its limited additive value, one could consider reserving the squatting-to-standing-test for patients with high clinical suspicion for $\mathrm{IOH}$, but with a negative lying-to-standing-test. However, one should keep in mind that the false-positive rate for the squatting-tostanding-test is even higher than for the lying-to-standing-test. This is presumably caused by the fact that the normal physiological drop in blood pressure during the squatting-to-standing-test is larger (on average $60 \mathrm{~mm} \mathrm{Hg}$ systolic and $40 \mathrm{~mm} \mathrm{Hg}$ diastolic in healthy individuals) as compared to that during the lying-to-standing test $[1,18]$. Therefore, it appears that the currently used cut-off for the squatting-to-standing test is not strict enough to accurately differentiate between $\mathrm{IOH}$ and a normal physiological response.

Given the high number of "false-positive" patients and the large number of healthy people meeting the blood pressure cut-off for IOH [15], the question arises whether a more stringent cut-off for IOH could improve its diagnostic value. Interestingly, a previous study among patients with Parkinson's disease suggested that the absolute nadir of blood pressure has a higher diagnostic value for detecting symptomatic orthostatic hypotension (thus with symptoms of cerebral hypoperfusion) than the change in blood pressure from baseline that is currently used [19]. Future studies among patients with symptomatic $\mathrm{IOH}$ as well as asymptomatic, age-matched controls are needed to evaluate whether this is also the case for $\mathrm{IOH}$ and whether the diagnostic criteria should be tightened.

In the present study, we were not able to point out clear risk factors for $\mathrm{IOH}$. The use of blood pressure lowering drugs and antidepressants among patients with $\mathrm{IOH}$ was high, but comparable to that in patients without IOH. However, in our experience and according to previous literature, interrupting blood pressure lowering drugs (especially beta- 
A

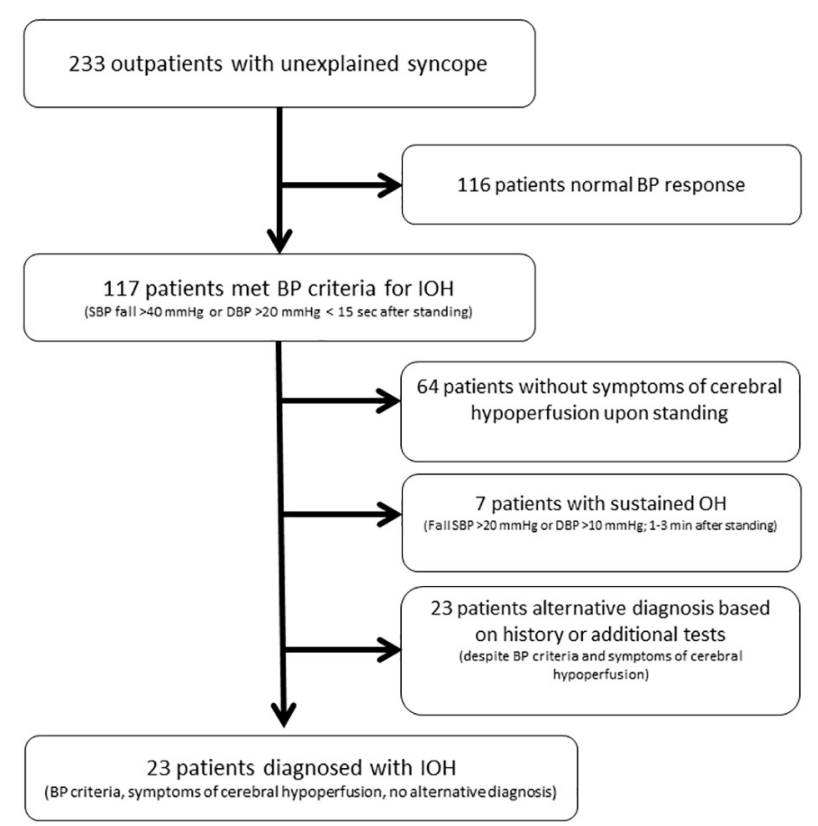

B

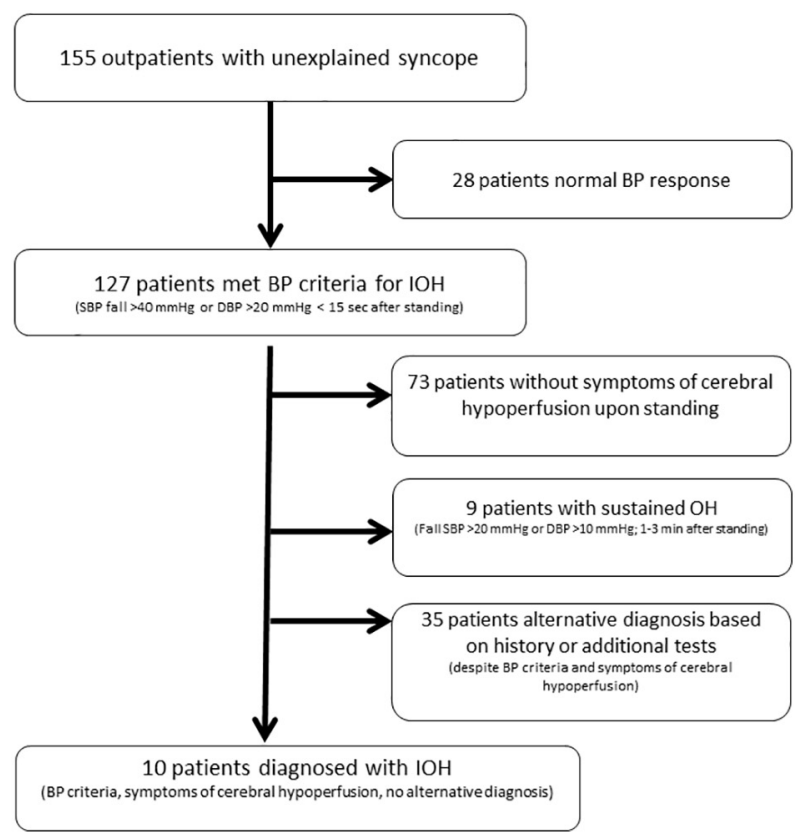



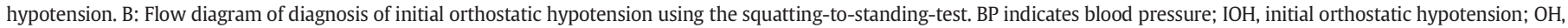
orthostatic hypotension.

blockers) [20] and antidepressants [21] could halt recurrent syncope in patients with $\mathrm{IOH}$. The negative analysis in this study might be caused by the fact that we did not use an appropriate control group, but only a comparison with patients who were referred because of unexplained syncope with different etiology. These patients were relatively frail and often used blood pressure lowering drugs. Therefore we presume that the negative analysis in this study does not indicate that blood pressure lowering drugs do not contribute to the development of $\mathrm{IOH}$, but merely that not all patients using blood pressure lowering drugs develop symptoms of IOH.

The present study is limited by the fact that we only performed a single measurement under semi-standardized conditions (in a clinical setting). As beat-to-beat blood pressure can vary over time [17], this may have led to under- or overdiagnosis of $\mathrm{IOH}$, especially in cases were blood pressure was just above or below the cut-off. However, as history taking played a major role in establishing the diagnosis, the risk for overdiagnosis is considered to be small. Finally, this study was performed in a selected population of outpatients referred to a specialized syncope unit in a tertiary hospital. Therefore, the prevalence of $\mathrm{IOH}$ in

Table 2

Diagnosis after evaluation in a multidisciplinary syncope unit.

\begin{tabular}{|c|c|}
\hline Diagnosis & $\mathrm{n}(\%)$ \\
\hline Reflex syncope & $77(33.0 \%)$ \\
\hline Initial orthostatic hypotension & $26(11.2 \%)$ \\
\hline Orthostatic hypotension & $25(10.7 \%)$ \\
\hline Stumbling ${ }^{\mathrm{a}}$ & $14(6.0 \%)$ \\
\hline Heart rhythm abnormality & $13(5.6 \%)$ \\
\hline Autonomic dysfunction & $7(3.0 \%)$ \\
\hline Psychogenic/hyperventilation & $7(3.0 \%)$ \\
\hline Sleep disorder & $7(3.0 \%)$ \\
\hline Vestibular dysfunction $^{\mathrm{a}}$ & $6(2.6 \%)$ \\
\hline Epilepsy $^{\mathrm{a}}$ & $5(2.1 \%)$ \\
\hline Other/multifactorial & $18(7.7 \%)$ \\
\hline Idiopathic syncope & $26(11.2 \%)$ \\
\hline
\end{tabular}

Diagnosis in 233 outpatients with previously unexplained syncope after evaluation in a multidisciplinary syncope unit in a tertiary health care center.

a By definition, stumbling, vestibular dysfunction, and epilepsy are no syncope as no global cerebral hypoperfusion occurs. this study cannot automatically be extrapolated to other clinical settings.

In conclusion, $\mathrm{IOH}$ is highly prevalent among outpatients with unexplained syncope referred to a tertiary hospitals syncope unit. Therefore, beat-to-beat blood pressure measurement during active standing should be considered in patients with unexplained syncope. However, as the false-positivity rate of such measurements is high, history taking remains the cornerstone in the evaluation of unexplained syncope. Future studies should evaluate whether different blood pressure cut-off points could improve the diagnostic value of these tests.

Supplementary data to this article can be found online at https://doi. org/10.1016/j.ijcard.2018.05.043.

\section{Acknowledgments}

The authors wish to thank the Department of Neurology for their contribution to the clinical evaluation of the patients.

\section{Sources of funding}

None.

\section{Disclosures/conflicts on interests}

None.

\section{References}

[1] W. Wieling, C.T. Krediet, N. van Dijk, M. Linzer, M.E. Tschakovsky, Initial orthostatic hypotension: review of a forgotten condition, Clin. Sci. (Lond.) 112 (3) (2007) 157-165.

[2] R. Freeman, W. Wieling, F.B. Axelrod, et al., Consensus statement on the definition of orthostatic hypotension, neurally mediated syncope and the postural tachycardia syndrome, Clin. Auton. Res. 21 (2) (2011) 69-72.

[3] F. Ammirati, F. Colivicchi, G. Minardi, et al., The management of syncope in the hospital: the OESIL Study (Osservatorio Epidemiologico della Sincope nel Lazio), G. Ital. Cardiol. 29 (5) (1999) 533-539.

[4] J.J. Blanc, C. L'Her, A. Touiza, B. Garo, E. L'Her, J. Mansourati, Prospective evaluation and outcome of patients admitted for syncope over a 1 year period, Eur. Heart J. 23 (10) (2002) 815-820.

[5] F.P. Sarasin, M. Louis-Simonet, D. Carballo, et al., Prospective evaluation of patients with syncope: a population-based study, Am. J. Med. 111 (3) (2001) 177-184. 
[6] M. Brignole, A. Ungar, A. Bartoletti, et al., Standardized-care pathway vs. usual management of syncope patients presenting as emergencies at general hospitals, Europace 8 (8) (2006) 644-650.

[7] L.R. Olde Nordkamp, N. van Dijk, K.S. Ganzeboom, et al., Syncope prevalence in the ED compared to general practice and population: a strong selection process, Am. J. Emerg. Med. 27 (3) (2009) 271-279.

[8] R.A. Kenny, M. Brignole, G.-A. Dan, et al., Syncope Unit: rationale and requirementthe European Heart Rhythm Association position statement endorsed by the Heart Rhythm Society, Europace 17 (9) (2015) 1325-1340.

[9] L.M. Sipkens, K. Treskes, K. Ariese-Beldman, D.P. Veerman, C. Boer, Application of Nexfin noninvasive beat-to-beat arterial blood pressure monitoring in autonomic function testing, Blood Press. Monit. 16 (5) (2011) 246-251.

[10] S.W. Keet, C.S. Bulte, C. Boer, R.A. Bouwman, Reproducibility of non-standardised autonomic function testing in the pre-operative assessment screening clinic*, Anaesthesia 66 (1) (2011) 10-14.

[11] S.W. Keet, C.S. Bulte, A. Sivanathan, et al., Cardiovascular autonomic function testing under non-standardised and standardised conditions in cardiovascular patients with type-2 diabetes mellitus, Anaesthesia 69 (5) (2014) 476-483.

[12] V.K. van Wijnen, M.P. Harms, I.K. Go-Schon, et al., Initial orthostatic hypotension in teenagers and young adults, Clin. Auton. Res. 26 (6) (2016) 441-449.

[13] N. van Dijk, K.R. Boer, N. Colman, et al., High diagnostic yield and accuracy of history physical examination, and ECG in patients with transient loss of consciousness in FAST: the Fainting Assessment study, J. Cardiovasc. Electrophysiol. 19 (1) (2008) 48-55.
[14] M. Shichiri, H. Tanaka, R. Takaya, H. Tamai, Efficacy of high sodium intake in a boy with instantaneous orthostatic hypotension, Clin. Auton. Res. 12 (1) (2002) 47-50.

[15] C. Finucane, M.D. O'Connell, C.W. Fan, et al., Age-related normative changes in phasic orthostatic blood pressure in a large population study: findings from The Irish Longitudinal Study on Ageing (TILDA), Circulation 130 (20) (2014) 1780-1789.

[16] C. Finucane, M.D. O'Connell, O. Donoghue, K. Richardson, G.M. Savva, R.A. Kenny, Impaired orthostatic blood pressure recovery is associated with unexplained and injurious falls, J. Am. Geriatr. Soc. 65 (3) (2017) 474-482.

[17] C. Finucane, G.M. Savva, R.A. Kenny, Reliability of orthostatic beat-to-beat blood pressure tests: implications for population and clinical studies, Clin. Auton. Res. 27 (1) (2017) 31-39.

[18] F. Rossberg, J. Peňaz, Initial cardiovascular response on change of posture from squatting to standing, Eur. J. Appl. Physiol. Occup. Physiol. 57 (1) (1988) 93-97.

[19] J.A. Palma, J.C. Gomez-Esteban, L. Norcliffe-Kaufmann, et al., Orthostatic hypotension in Parkinson disease: how much you fall or how low you go? Mov. Disord. 30 (5) (2015) 639-645.

[20] M. Canney, M.D. O'Connell, C.M. Murphy, et al., Single agent antihypertensive therapy and orthostatic blood pressure behaviour in older adults using beat-to-beat measurements: The Irish Longitudinal Study on Ageing, PLoS One 11 (1) (2016), e0146156.

[21] W. Wieling, M.P. Harms, R.A. Kortz, M. Linzer, Initial orthostatic hypotension as a cause of recurrent syncope: a case report, Clin. Auton. Res. 11 (4) (2001) 269-270. 